\title{
In Search of Reliable Persuasion Effects: III. The Sleeper Effect is Dead. Long Live the Sleeper Effect.
}

\author{
Anthony R. Pratkanis \\ University of California \\ Michael R. Leippe \\ Adelphi University
}

\author{
Anthony G. Greenwald \\ University of Washington \\ Michael H. Baumgardner \\ Burke Marketing Services Inc. \\ Cincinnati, Ohio
}

\begin{abstract}
The sleeper effect in persuasion is a delayed increase in the impact of a message that is accompanied by a discounting cue. Despite a long history, the sleeper effect has been notoriously difficult to obtain or to replicate, with the exception of a pair of studies by Gruder et al. (1978). We conducted a series of 16 computer-controlled experiments and a replication of the Gruder et al. study to demonstrate that a sleeper effect can be obtained reliably when subjects (a) note the important arguments in a message, (b) receive a discounting cue after the message, and (c) rate the trustworthiness of the message communicator immediately after receiving the discounting cue. These operations are sufficiently different from those used in earlier studies to justify a new differential decay interpretation of the sleeper effect, in place of the dissociation hypothesis favored by most previous sleeper effect researchers. According to the differential decay interpretation, a sleeper effect occurs when message and discounting cue have opposite and near-equal immediate impacts that are not wellintegrated in memory. The effect occurs, then, if the impact of the discounting cue decays faster than that of the message.
\end{abstract}

A sleeper effect in persuasion is a delayed increase in the impact of a persuasive message. The term was first used by Hovland, Lumsdaine, and Sheffield (1949) to describe opinion change produced by the U.S. Army's Why We Fight films used during World War II. As a pattern of data, the sleeper effect is opposite to the typical finding that experimentally induced opinion change dissipates over time (Cook \& Flay, 1978). As such, the sleeper effect is an "interesting quirk" that has attracted much research and textbook attention.

Early in its history, the sleeper effect became identified with the dissociation hypothesis and was defined as a delayed increase in persuasive impact that occurs as a result of a persuasive message accompanied by a discounting cue. Close scrutiny of previous sleeper effect research, however, reveals that much

This research was supported by National Science Foundation grants SOC 74-13436, BNS 76-11175, BNS 82-17006, and National Institute of Mental Health grant MH 32317, all entitled Research in Persuasive Communication. The research was conducted while all authors were at Ohio State University.

The authors thank Mahzarin R. Banaji, Susan L. Schechtman, and Scott Teagarden for assistance in collecting data, Charles Gruder for supplying the materials used in the Gruder et al. (1978) study, Shelly Chaiken, Alice H. Eagly, William J. McGuire, and Richard E. Petty for the use of their persuasive messages, and Steven J. Breckler, Mary Brickner, Mitzi Johnson, David L. Ronis, and Marlene E. Turner for comments on a preliminary draft of this paper.

Correspondence concerning this article should be addressed to Anthony R. Pratkanis, Board of Psychology, University of California, Santa Cruz, California 95064. of the evidence for a sleeper effect is unsatisfactory and that the effect is difficult to obtain. The goals of the research presented in this article are, first, to specify empirical operations capable of producing a reliable sleeper effect and, secondly, to describe the sleeper effect in theoretical terms that can guide a search for other conceptually similar and effective operations.

\section{Nomenclature}

Figure 1 displays four data patterns that appear frequently in a sleeper effect research. Each is a persistence-of-persuasion function: a relation between measurement delay following a persuasive communication and opinion. The most common persistence function is the decay of persuasion that typically occurs for effective communications (Figure 1A). The sleeper effect pattern is one that starts at or above the preopinion level and shows an increase in persuasion with measurement delay (Figure 1B). A boomerang effect occurs when a communication initially changes opinion in an opposite-from-intended direction. The nonpersisting boomerang effect (Figure 1C), although taking the form of a delayed increase in agreement with the communication, is conceptually more similar to decay of (negative) persuasion than it is to the sleeper effect.

The relative sleeper effect (Figure 1D; Cook, 1971; Cook, Gruder, Hennigan, \& Flay, 1979) involves two juxtaposed persistence-of-persuasion functions, one showing decay of persuasion and the other showing both less initial impact and less (or no) decay. In a typical experiment that produces the relative sleeper effect pattern, decay of persuasion occurs for a communication from a highly credible source, whereas a lower and 


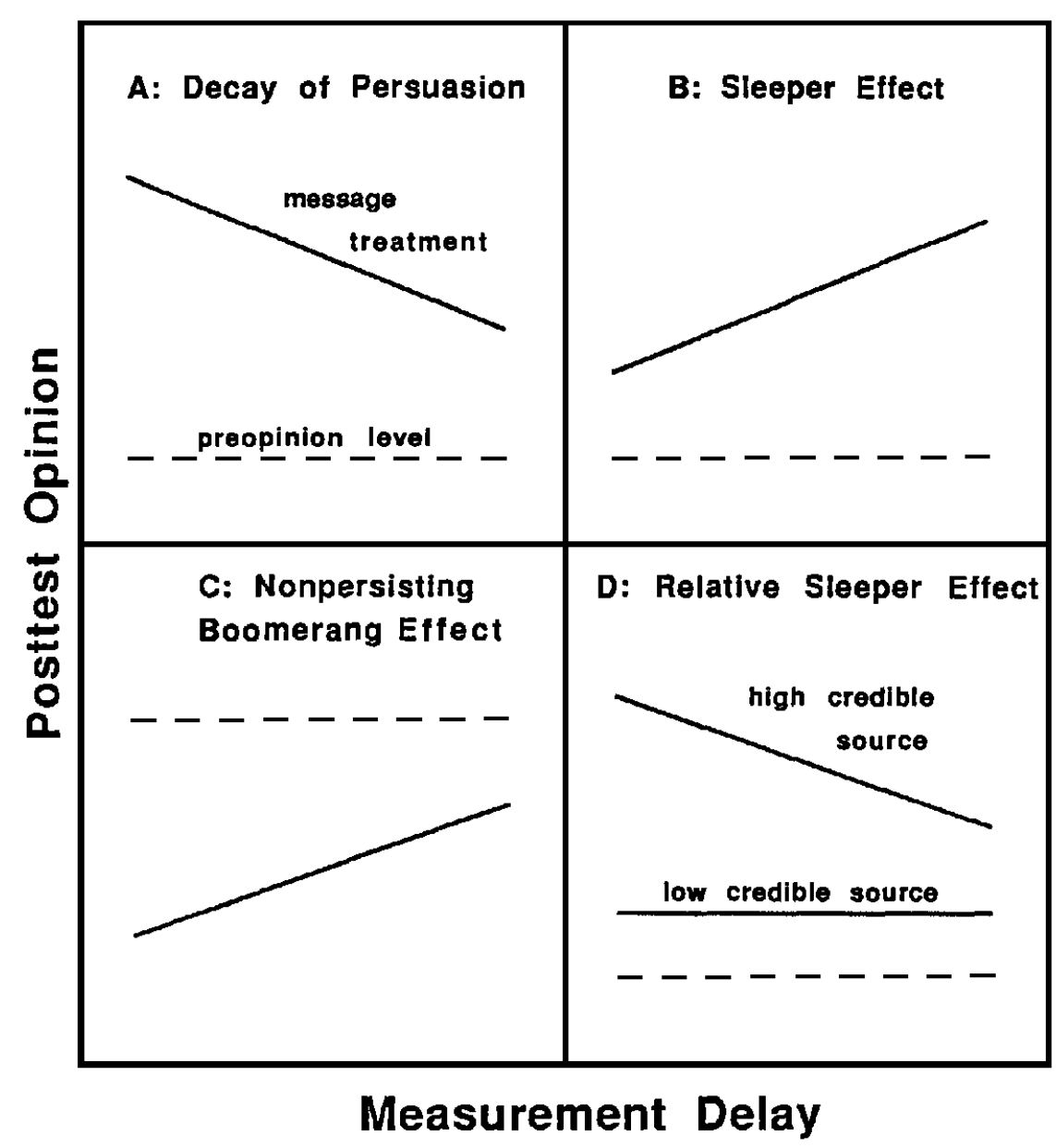

Figure 1. Data patterns for experiments on persistence of persuasion. (Each panel describes posttest opinion as a function of measurement delay following a persuasive communication.)

flatter function is obtained for a communication from a lowcredibility source. The relative sleeper effect involves a loss of differential effects of high- and low-credibility sources, but without any delayed increase in impact for either source. Cook et al. (1979) refer to the sleeper effect proper (Figure 1B) as an absolute sleeper effect, to distinguish it from the relative sleeper effect pattern.

\section{Evolution of a Forgetting Interpretation}

Although many explanations of the sleeper effect have been advanced (see McGuire, 1985, and Pratkanis, 1981, for reviews), interpretations based on forgetting and memory processes have been most popular.

\section{Original Forgetting Hypothesis}

Hovland, Lumsdaine, and Sheffield proposed four explanations for their original delayed persuasion findings, but it was their source forgetting interpretation that set the stage for future sleeper effect research. According to their hypothesis, "forgetting is the rule but the source of an item of information is more quickly forgotten than the material presented" (Hovland et al., 1949, p. 196). Hovland et al. noted that a sleeper effect would be most likely to occur in a situation where message "content was very well presented but where the source was suspect" and "when what is remembered and what is believed are kept separate [in memory]" immediately after message presentation (p. 197).

\section{Dissociation Interpretation}

In a study designed to test the source forgetting interpretation of the sleeper effect, Hovland and Weiss (1951) found that a majority of subjects (including those in the sleeper effect treatment) were able to recall the source of the message. To account for these findings, Hovland and Weiss introduced the dissociation discounting cue hypothesis (which was subsequently advocated by Kelman \& Hovland, 1953; Weiss, $1953^{1}$ and Hovland,

\footnotetext{
${ }^{I}$ The Weiss (1953) study also advocated the adoption of differential loss between source treatments or a relative sleeper effect as the empirical criterion for a sleeper effect, as opposed to the absolute effect criterion used in previous studies.
} 
Janis, \& Kelley, 1953). According to the dissociation interpretation, a sleeper effect occurs when a persuasive message is presented with a discounting cue (such as a low-credible source or a counterargument). At immediate posttest opinion measurement, the recipient recalls both message and discounting cue (i.e., both are associated in memory together), resulting in little or no opinion change. After a delay, as the association between message and discounting cue weakens the recipient may "remember what was said without thinking about who said it" (Hovland et al., 1953, p. 259). In other words, a sleeper effect occurs because of a spontaneous dissociation of a message and a discounting cue over time (as opposed to a simple forgetting of source). Source information may be recalled, but it is not readily associated with the message content when opinions are queried.

\section{Logical Requirements of the Dissociation Hypothesis}

In an unpublished work, Cook (1971) critically reviewed 13 experiments considered relevant for a test of a sleeper effect and found little evidence for the absolute sleeper effect (see also Capon \& Hulbert, 1973). A series of experiments conducted by Gillig and Greenwald (1974) is representative of many past sleeper effect studies. In their seven separate tests of the sleeper effect, which involved 656 subjects, Gillig and Greenwald found evidence for the relative sleeper effect but not for the sleeper effect proper. Gillig and Greenwald's failure to produce an absolute sleeper effect is consistent with the results of other studies that presented a discounting cue with an otherwise effective persuasive message (cf. Chaiken, 1980; Hennigan, Cook, \& Gruder, 1982; Maddux \& Rogers, 1980; Whittaker \& Meade, 1968).

In response to these null results, Gruder et al. (1978; see also Cook et al., 1979) specified the following four logical conditions or requirements that must be met to test for a sleeper effect based on the dissociation hypothesis:

(a) a persuasive message must have substantial initial impact on attitudes; (b) this change is totally inhibited by a discounting cue; (c) the cue and message are dissociated over time; and (d) the cue and message are dissociated quickly enough so that the message by itself still has some impact when dissociation occurs. (p. 1074)

In a series of experiments, Gruder et al. (1978) obtained sleeper effects when these requirements were met and, just as importantly, failed to obtain such an effect when they were not.

\section{Overview of the Research}

Although the Gruder et al. logical requirements clarify the circumstances under which a sleeper effect should occur according to a dissociation hypothesis, the requirements do not specify empirical operations that are capable of producing a sleeper effect. In the research presented here, we sought to identify a set of successful operations for obtaining a sleeper effect. We began, not by questioning the dissociation hypothesis but by hypothesizing that the sleeper effect is a small effect requiring a powerful research design for detection. In the research that followed, this hypothesis progressed through five stages of research (in response to our own findings and those of Gruder et al., 1978), leading us to adopt a new, differential decay interpretation of the sleeper effect.

Table 1 identifies these phases and summarizes 17 sleeper effect experiments. Among those 17 experiments, there were 29 treatments that tested for the occurrence of a sleeper effect. In Table 1, each sleeper-effect test is described in terms of the following: (a) main features of procedures, (b) measurement delays investigated, (c) number of subjects, (d) number of observations per subject in the within-subjects design, (e) the study's power to detect an effect having a magnitude of $20 \%$ of the standard deviation of observed change or increase scores, and (f) the magnitude of observed effect on the sleeper effect test. ${ }^{2}$

\section{General Methods for Experiments 1-16}

\section{Subjects}

The 478 subjects participating in Experiments 1-16 were either students in an introductory psychology course, who received course credit for their participation, or respondents to an advertisement in a student newspaper, who received $\$ 4.00$ for their participation. Table 1 presents the number of subjects that participated in each experiment.

\section{Equipment}

The experimental apparatus consisted of a minicomputer and four subject stations, each equipped with a video display monitor and response keyboard (see Baumgardner, Leippe, Ronis, \& Greenwald, 1983, and Ronis, Baumgardner, Leippe, Cacioppo, \& Greenwald, 1977, for more details). During the experiment, the computer located disk-stored text materials (such as instructions, messages, and measures), displayed them on a video monitor, and recorded subjects' responses. The computer also counterbalanced the assignment of topics to treatments and randomized the sequence of experimental events within design restrictions.

\section{Persuasive Materials}

\section{Persuasive Messages}

The first 16 experiments used three sets of messages: a set of consumer product messages (Experiments 1-7 and 12); a set of short policyissue messages (Experiments 8-11 and 13-14); and a set of long policyissue messages (Experiments 15-16). The Appendix presents an example of each of the three types of persuasive communications along with discounting and accepting cues and opinion measures (see Pratkanis, Greenwald, Ronis, Leippe, \& Baumgardner, 1986, for the complete sets of messages).

Each policy message consisted of arguments advocating one side of a sociopolitical issue. For example, messages argued that coal should not be used as a primary energy source, textbooks should be free in public schools, and Puerto Rico should not be admitted to the Union as a state. Pretesting established that subjects did not possess strong initial opinions on these topics and found them at least moderately interesting.

\footnotetext{
${ }^{2}$ Each observed effect size $(d)$ in Table 1 was computed (after Cohen, 1977) by dividing the observed slope of the linear trend of the persistence function by the standard deviation of that slope estimate. Positive values of this $d$ statistic indicate a sleeper effect and negative values indicate ordinary decay of persuasion. The $d$ values of $.20, .50$, and .80 correspond to effects that Cohen classifies, respectively, as small, medium, and large.
} 
Table 1

Summaries of 17 Sleeper Effect Experiments

\begin{tabular}{|c|c|c|c|c|c|c|c|}
\hline Main feature of experiment & Test & $\begin{array}{l}\text { Timing of } \\
\text { source }^{\mathrm{a}}\end{array}$ & $\begin{array}{c}\text { Range of } \\
\text { measurement delay }\end{array}$ & $N$ & $\begin{array}{l}\text { Observations } \\
\text { per subject }\end{array}$ & $\begin{array}{c}\text { Power } \\
(d=.2)^{\mathrm{b}}\end{array}$ & $\begin{array}{l}\text { Observed } \\
\text { effect }^{s}\end{array}$ \\
\hline \multicolumn{8}{|c|}{ Phase 1: Searching for a small sleeper effect } \\
\hline $\begin{array}{l}\text { Exp. 1-4: First use of computerized procedure; } \\
\text { consumer messages attributed to Consumer } \\
\text { Reports (high) or manufacturer (low) }\end{array}$ & $\begin{array}{l}1 \\
2 \\
3 \\
4\end{array}$ & $\begin{array}{l}\text { just pre } \\
\text { just pre } \\
\text { just pre } \\
\text { just pre }\end{array}$ & $\begin{array}{l}0-13.5 \\
0-13.5 \\
0-13.5 \\
0-13.5\end{array}$ & $\begin{array}{l}12 \\
12 \\
12 \\
12\end{array}$ & $\begin{array}{l}16 \\
16 \\
16 \\
16\end{array}$ & $\begin{array}{l}.50 \\
.50 \\
.50 \\
.50\end{array}$ & $\begin{array}{r}-.06 \\
.00 \\
-.07 \\
-.01\end{array}$ \\
\hline
\end{tabular}

Phase 2: Investigating the timing of the cue presentation

Exp. 5: Variation of source timing (immed. before vs. immed. after)

Exp. 6: Repeat Exp. 6 with wider range of msmt. delays

Exp. 7: Greater separation of source from message

Exp. 8: Individually randomized procedure; simulated talk show

Exp. 9: Attempt to replicate Test 12's sleeper effect (in Test 15)

Exp. 10: New source variation; writer reports information source

Exp. 11: Attempt to replicate Test 16's sleeper effect (in Test 18)

Exp. 12: Near exact replication of Exp. 7; attempt to replicate Test 11 's effect (in Test 22)

Exp. 13: Add to message impact by using cognitive response procedure

Exp. 14: add immed. rating of source (a la Gruder et al., 1978)

Exp, 15: Stronger messages

Exp. 16: Enhancement of credibility manipulation

$\begin{array}{lll}\text { just pre } & 0-13.5 & 24 \\ \text { just post } & 0-13.5 & 24 \\ \text { just pre } & 0-20 & 24 \\ \text { just post } & 0-20 & 24 \\ 2 \text { units pre } & 0-20 & 24 \\ \text { just pre } & 0-20 & 24 \\ 2 \text { units post } & 0-20 & 24 \\ 1 \text { unit post } & 0-9 & 40 \\ 2 \text { units post } & 0-9 & 40 \\ 1 \text { unit pre } & 0-9 & 60 \\ 1 \text { unit post } & 0-9 & 60 \\ 1 \text { unit pre } & 0-9 & 40 \\ 1 \text { unit post } & 0-9 & 40 \\ 1 \text { unit pre } & 0-9 & 40 \\ 1 \text { unit post } & 0-9 & 40 \\ 2 \text { units pre } & 0-9 & 36 \\ \text { just pre } & 0-9 & 36 \\ 2 \text { units post } & 0-9 & 36\end{array}$

Phase 3: Designing a sleeper effect

\begin{tabular}{|c|c|c|c|c|c|c|}
\hline 23 & 1 unit post & $0-9$ & 20 & 10 & .51 & +.02 \\
\hline 24 & 1 unit post & $0-9$ & 60 & 10 & .93 & $+.08^{*}$ \\
\hline \multicolumn{7}{|c|}{ Phase 4: Replicating the sleeper effect } \\
\hline $\begin{array}{l}25 \\
26\end{array}$ & $\begin{array}{l}1 \text { unit post } \\
1 \text { unit post }\end{array}$ & $\begin{array}{l}0-9 \\
0-9\end{array}$ & $\begin{array}{l}22 \\
40\end{array}$ & $\begin{array}{l}11 \\
10\end{array}$ & $\begin{array}{l}.59 \\
.81\end{array}$ & \\
\hline
\end{tabular}

Phase 5: Replicating the sleeper effect with converging operations

Exp. 17: Exact (noncomputer) replication of Gruder et al. (1978) with the cue given before (Test 27) and after (Test 29) Gruder's message plus a shortened version (Test 28)

$\begin{array}{lllllll}27 & \text { before } & 6 \text { weeks } & 62 & 2 & .35 & \frac{-.08}{+.23} \\ 28 & \text { after } & 6 \text { weeks } & 62 & 2 & .35 & \underline{+.30^{*}} \\ 29 & \text { after } & 6 \text { weeks } & 54 & 2 & .31 & \underline{\underline{w}^{*}}\end{array}$

a Discounting cues (information undermining message's credibility) were presented either at the top of the display (just pre) or on displays before or after the message.

${ }^{\mathrm{b}} d$ is the effect size index, which equals estimated slope of the persistence function divided by standard deviation of tliat slope estimate. Power is at alpha $=.05$, two-tailed.

${ }^{\circ}$ Observed effects are in $d$ units (see Note b). Italicized effect sizes are for treatments in which the discounting cue came after the message (see Note a).

d Experiment 16 did show a sleeper effect at the early delay ranges. The effect size given here is for the entire range of measurement delays.

* Significant sleeper effect, $p<.05$, two-tailed.

The 20 short messages (averaging about 80 words each) consisted of a title announcing the conciusion of the message and two arguments in support of one side of the issue. The 22 long messages (averaging about 150 words each) began with a question (e.g., "Should Puerto Rico be made a state of the Union?"). Each sentence of the message then presented an argument in support of one side of the issue with the last sentence stating the message conclusion.
The consumer messages linked a fictitious brand name with 1 of 12 product categories and with a brand evaluation that could range from very negative to very positive. Each consumer message began with a title announcing the brand name and product category. The body of the message consisted of two (approximately) 50-word paragraphs, each discussing a product attribute (e.g., the braking ability of automobiles or the fringe reception of televisions). Each paragraph concluded with 
a one- or two-sentence rating of a fictitious brand on the attribute discussed in that paragraph (e.g., Miller Television sets have excellent fringe reception).

\section{Discounting and Accepting Cues}

Each long and short policy message had its own discounting and accepting cue (each averaging about 30 words in length). These cues restated the conclusion of the message and either attacked (discounting cue) or bolstered (accepting cue) the credibility of the message's source. The consumer messages were discounted by identifying the message source as the manufacturer (a low-credible source). The magazine Consumer Reports (a high-credible source) served as the accepting cue for the consumer messages. The computer implemented a counterbalancing procedure that permuted message cues across messages topics once every 12 subjects for consumer messages and once every 20 (or 22, as in Experiment 15) subjects for the policy issues.

\section{Opinion Measures}

Opinion measures for the short policy messages asked subjects to rate the conclusion of each message on a 15-point scale of agreement (ranging from 1 = strongly disagree to $15=$ strongly agree). Opinion measures for the long policy messages requested that subjects answer the message's introductory question on a 9-point scale (ranging from 1 = certainly not to $9=$ certainly yes). Some of the opinion measures for the longer policy messages were reversed to reduce any response set bias. Opinion measures for the consumer messages asked subjects to rate the brand of product on a 15 -point scale (ranging from $1=$ very poor to $15=$ excellent).

\section{Procedures}

\section{Policy Message Experiments}

Figure 2 presents an outline of the procedures used in policy issue studies. In these studies, subjects first viewed a series of introductory displays that (a) described the experiment as concerned with interactive communications systems, (b) provided practice entering responses, (c) presented informed consent information, and (d) supplied information specific to each experiment. Subjects then viewed a series of text displays presenting a simulated television talk show called "You Should Know." This show featured an emcee who introduced letters presumably written by previous viewers of the show (the persuasive messages) for the current audience (the subject) to evaluate.

During the first part of the simulated talk show, each subject provided their pretreatment opinions (using the same scale as in the posttest assessment) on a subset of experimental topics selected by a counterbalancing routine. Next, subjects viewed the persuasive materials and provided their opinion on each topic. Each subject received a different random presentation of messages and measures to minimize order effects. The session concluded with debriefing information and an opportunity to discuss the study with the experimenter. Subjects worked at a selfpaced rate and took between $30 \mathrm{~min}$ and 1 hour to complete the tasks.

\section{Consumer Message Experiments}

Studies using the consumer messages followed a procedure similar to those used in the policy message studies, with three exceptions. First, because these messages concerned fictitious brands of products, pretreatment opinions were not assessed (and could be assumed to be near the midpoint of the opinion scale). Second, with the exception of Experiment 12, which used the randomization procedure for measurement delays, the consumer products studies used a few (typically three or four) arbitrary sequences of messages and measures, which were prepared and presented to different groups of subjects within a single experimental replication. Finally, the consumer experiments did not use the simulated talk show format. Instead, subjects received instructions that described the experiment as concerned with responses to short messages discussing brands of various commercial products. Subjects were then

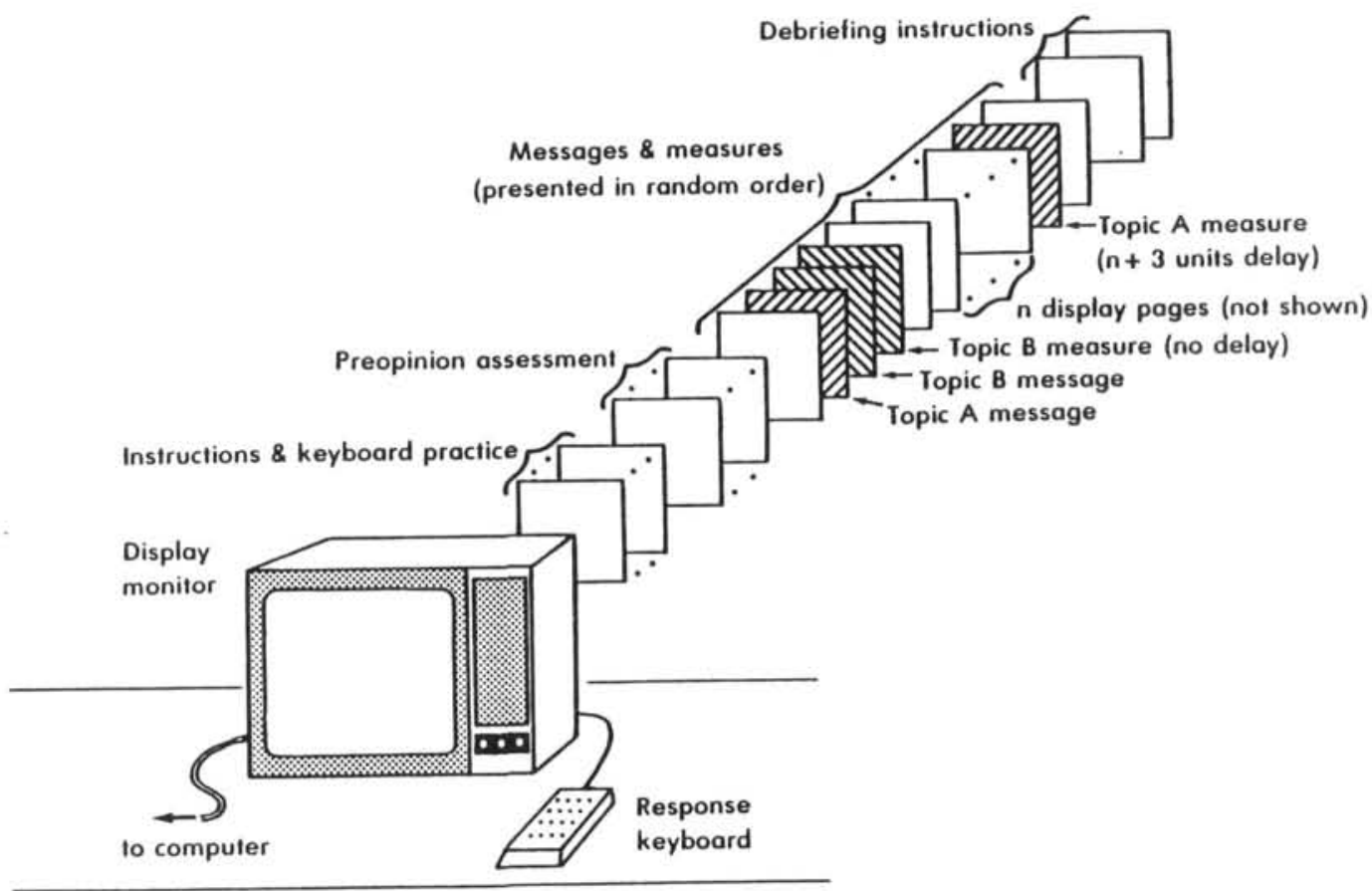

Figure 2. Schematic presentation of computer-controlled persuasion procedures used in policy message experiments (Experiments 8-11 and 12-16). 
asked to attend to the brand messages but to make no special attempt to study or memorize the materials.

\section{Independent Variable of Measurement Delay}

The presentation of short messages in close succession made it possible to investigate the persistence of persuasion within a single session. In previous computer-controlled experiments, Baumgardner et al. (1983) found that persuasive effects decayed rapidly in their message-dense environment, particularly when topics were similar in nature. As in previous studies using these procedures, measurement delay was determined by the number of activity units (displays to which the subject must respond) between a message and its measure (see Figure 2). In studies using the randomization routine, the order of message and measure presentation was constrained such that a measure was always displayed after its message. Thus, for these studies, measurement delay was randomly determined for each topic with values ranging from 0 to 9 activity units. $^{3}$

\section{Phase 1: Searching for the Sleeper Effect With Improved Procedures}

One possible reason for Gillig and Greenwald's (1974) failure to obtain a sleeper effect is that their procedures may not have been capable of detecting a sleeper effect. The Ronis et al. (1977) laboratory procedure (described previously) includes the following advantages: (a) computerized control over presentation of up to 50 short persuasive messages in a single hourlong session; (b) message topics selected from a large population of topics to which it would be possible to generalize results; (c) use of within-subjects designs to increase power to detect effects that, although small, might be important in mass communication settings; and (d) use of varied within-session measurement delays, permitting observation of persistence-of-persuasion functions within a single session. In the first four experiments we attempted to use these computerized procedures either to obtain a (presumably small) sleeper effect or to demonstrate that the sleeper effect could not be obtained even with the methodological advances of the new procedures.

\section{Experiments 1-4}

\section{Method}

In Experiments 1-4, subjects viewed consumer messages in a 2 (source credibility: low or high) $\times 4$ (measurement delay) $\times 4$ (internal replication: 4 within-session blocks) design. All experimental messages presented a strongly positive evaluation of a fictitious brand of product. Each subject received such persuasive messages for 32 fictitious brands, 8 from each of four product categories in Experiments 1-3 and 16 messages from each of two product categories in Experiment 4. To decrease the homogeneity of messages within a session, we used filler messages on other brands of products that presented a variety of evaluations and were followed by immediate posttests. The source information (either the manufacturer as a low-credible source or Consumer Reports as a high-credible source) was always given at the top of a display page fol- lowed by the message. The only variation among the four experiments was an adjustment of the source descriptions given in the introductory instructions (in Experiments 2-4), so that low-credible sources would be viewed as more untrustworthy and thus produce immediate postmessage opinions that were as near as possible to the midpoint of the scale.

\section{Results}

The results of Experiments 1-4 are shown in Panels A-D of Figure 3. As can be seen, the relative sleeper effect pattern was much in evidence in all four studies, but there was no sign of the sleeper effect proper. Consumer messages attributed to the low-credible source were rated lower than were those attributed to the high-credible source (all $p s<.001$ ). Immediate posttest opinion was closer to the scale midpoint in Experiments 2-4, which used the stronger low-credible source procedures. Nevertheless, in none of the replications was any significant or nearsignificant trend toward a sleeper effect apparent. That is, there was no tendency toward a significant positive trend in any of the discounting cue treatments (all slopes were either negative or $F \mathbf{s}<1$ ). The impact of messages attributed to the high-credible source decayed significantly (all $p s<.05$ ).

\section{Phase 2: Investigating the Timing of Cue Presentation}

The Gruder et al. (1978) experiments used a novel procedure in producing a sleeper effect: The discounting cue followed (as opposed to preceded) the persuasive message. In their studies, subjects read a persuasive message arguing against the 4-day work week. As they read, subjects underlined the important arguments in each paragraph of the message. A short disclaimer followed the communication and declared it to be false. Before giving their immediate postmessage opinions, subjects rated the trustworthiness of the message source. To test this potentially critical role of timing of the discounting cue, we designed Experiments $5-12$ to vary whether information about the communication's source came before or after the message. Four of these experiments are presented as examples of this phase of the research (see Table 1 for information about the other four).

\footnotetext{
${ }^{3}$ The opinion data from studies in which measurement delay was fixed by the experimenter were analyzed as described in Ronis, Baumgardner, Leippe, Cacioppo, \& Greenwald (1977). The opinion data from studies in which measurement delay was randomly determined were analyzed using hierarchical multiple regression for repeated measures design (see Cohen \& Cohen, 1975). The first step in the hierarchical regression removed the effects of variance due to subject and topic, which were represented by sets of dummy-coded variables. Subsequent steps were conducted using the residuals from this first step. The persistence of persuasion in each discounting cue or control treatment was described by a regression equation that predicted opinion from measurement delay. A sleeper effect would take the form of a positive regression coefficient (slope) that is significantly different from zero.
}

Figure 3. Results of selected computerized experiments. (Sleeper effects were difficult to obtain, but occurred in experiments described by Panels G, J, and L. The scale ranges from 1 to 15 in Panels A-J and 1 to 9 in Panels $\mathrm{K}-\mathrm{L}$, with larger numbers representing more persuasion.) 


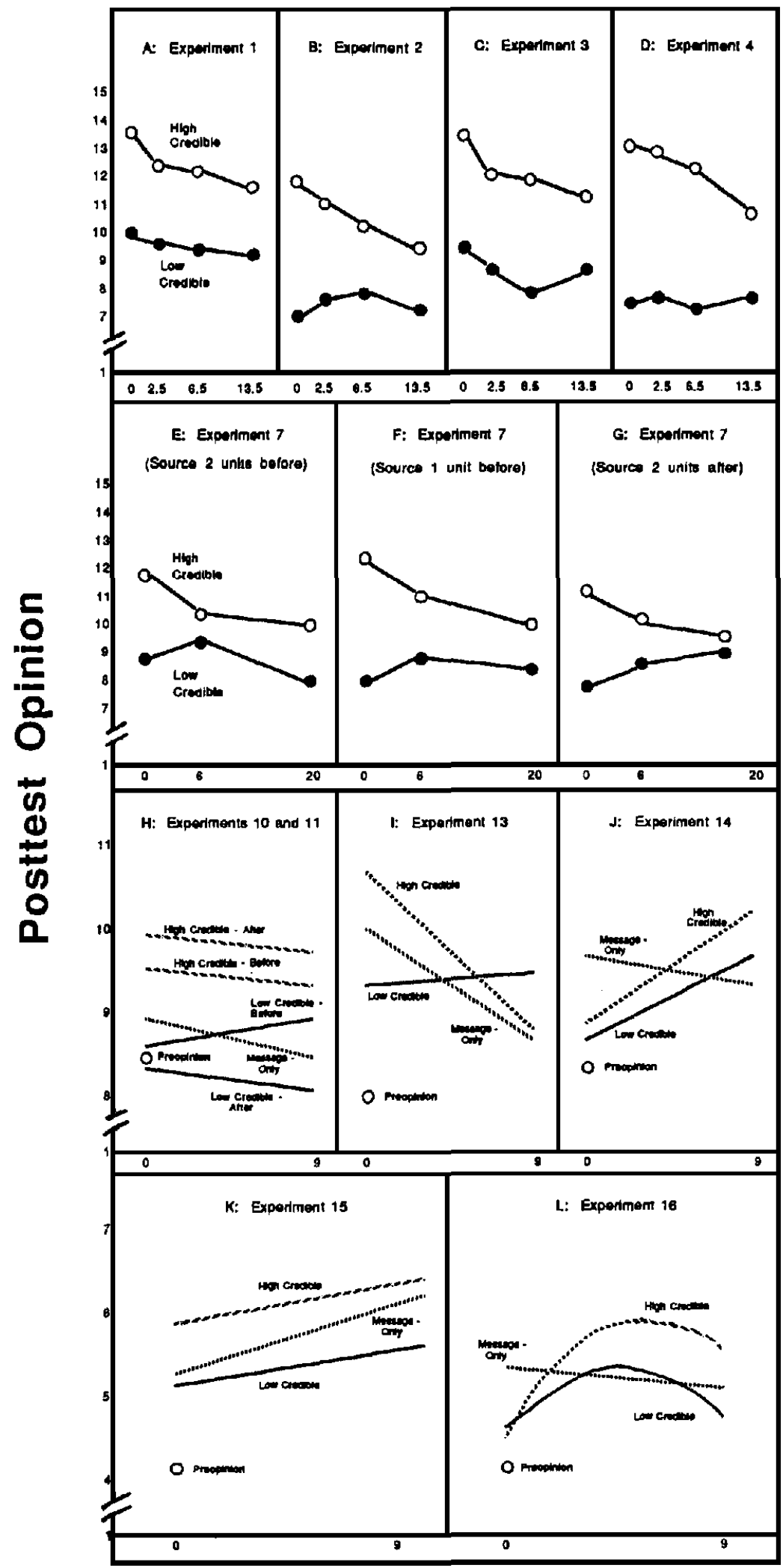

Measurement Delay 


\section{Experiment 7}

Experiments 5 and 6 were the first attempts to obtain a sleeper effect by varying the timing of the discounting cue. In these two studies, the low-credible source of the message was identified on the display immediately below the presentation of the message. A significant sleeper effect did not occur in either of these two studies. Experiment 7 was based on the possibility that presenting the source immediately after the message may not effectively differ from simultaneous presentation of source and message. That is, when source information is given immediately after (and on the same display screen as) the message, it is possible for subjects to examine this information before reading the message or to hold the message conclusion in short-term memory while awaiting the source information. Thus, for Experiment 7 we used a longer separation between message and source presentations.

\section{Method}

In Experiment 7, subjects viewed consumer messages presented in a 2 (source credibility: low or high) $\times 3$ (measurement delay) $\times 3$ (timing of source presentation: before the message, on the same page as the message or 2 units after the message) design. With the exception of the source timing variation, the specific features of the design (e.g., number of messages, the use of positive and filler messages, source manipulation) resembled those used in Experiment 4. As in all studies that used a cue-after-message manipulation, measurement delay for each message was counted from the completion of relevant information (message and cue) for that brand. We anticipated that the frequent separation between source information and corresponding messages would appear odd to subjects. Instructions were presented at the beginning of the experiment explaining that this aspect of the study was an attempt to capture the complexity of the consumer's everyday information processing task.

\section{Results}

Panels E, F, and G of Figure 3 present the results from Experiment 7. As in the first six experiments, messages attributed to a high-credible source resulted in more persuasion than those attributed to a low-credible source (all $p$ s $<.01$ ). However, unlike the previous studies, a significant sleeper effect was obtained (assuming that preopinion is at or near the midpoint of the scale). That is, a significant increase in opinion occurred as a function of measurement delay when information about a lowcredible source was presented 2 units after the message, $F(1$, $22)=12.16, p<.01$. For the low source-before-message treatment, the linear trend showed a significant decrease in opinion as a function of delay, $F(1,22)=10.80 p<.01$; for the low source-with-message treatment, no significant trend was detected. All three high-credible source treatments produced substantial opinion change that dissipated as a function of measurement delay.

\section{Experiments 10 and 11}

In Experiments 8-11, we sought to determine if the Experiment 7 sleeper effect would generalize to the policy issues. In Experiment 8 a sleeper effect occurred with the short policy messages when a discounting cue was placed one unit after the message. However, this effect was not replicated in Experiment 9. In Experiments 10 and 11, we tried again to use the timing of source manipulation to produce a sleeper effect.

\section{Method}

In Experiments 10 and 11 , subjects viewed the short policy messages in a 2 (source credibility: low or high) $\times 2$ (timing of source: just before or just after the message) $\times 10$ (measurement delay) design. (A preopinion assessment and a message-only treatment in which subjects received no cue were also included.) We timed the source presentations by placing the message and source on adjacent displays. After viewing either the message or source information, subjects pressed a response button to view the rest of the materials for that topic. Except for a variation in preopinion assessment, the two studies were identical. The preopinion assessment in Experiment 10 consisted of a 15-point rating scale accompanied by the conclusion of a policy message. Subjects in Experiment 11 received this, plus brief statements of two opposing arguments (not used in the actual experiment) to serve as a context for their responses.

\section{Results}

Figure $3 \mathrm{H}$ presents the best fitting regression line predicting opinion from measurement delay for Experiments 10 and 11 combined. With one exception, the results were similar for both studies. Subjects agreed significantly more with messages from high-credible sources than from low-credible sources, $l(79)=$ $5.79, p<.01$, combined studies. This impact neither significantly increased nor decreased when the message was attributed to a high-credible source, when the message was given without a source (message-only), and when a low-credible source was given after the message (all linear trend tests, both individual and combined, were not significant, $p s>.1$ ). The results of the two studies diverged in the low-source-before-message treatment. In Experiment 10, a significant sleeper effect was obtained in this treatment, $t(39)=2.50, p<.05$. In Experiment 11 , opinion in this same treatment dissipated as a function of measurement delay, $t(39)=1.37, p<.1$. When the results of the two studies are averaged (as in Figure $3 \mathrm{H}$ ), opinion in the low-source-before treatment shows a small and nonsignificant increase across measurement delay; that is, no sleeper effect occurred, $t(79)=0.60, n s$.

\section{Experiment 12}

Because of the infrequency of finding (and replicating) significant sleeper effects, we conducted a close replication of Experiment 7 , which had obtained a significant sleeper effect.

\section{Method}

Experiment 12 is an almost exact replication of Experiment 7, except that we independently randomized the order of messages and measures for each subject in Experiment 12 (in contrast with the use of only three levels of measurement delay in Experiment 7).

\section{Results}

With one exception, the results of Experiment 12 were similar to those of Experiment 7. Messages from high-credible 
sources continued to produce more opinion change than those from low-credible sources. For the most part, persuasion either decayed or persisted for the high-credible sources. Opinion decayed in the low cue-before-message treatment (but not significantly) and did not vary as a function of measurement delay in the low source-with-message treatment. However, we did not obtain a sleeper effect in the low source-after-message treatment; although the slope of the linear trend was positive, it was small and nonsignificant, $F(1,35)<1$.

\section{Phase 3: Designing a Sleeper Effect}

Although the variable of source timing has been considered an important determinant of the sleeper effect, the previous experiments indicated that it is certainly not the sole determinant. The logical requirements specified by Gruder et al. (1978) indicated two other criteria for a sleeper effect: (a) the message should have persisting impact and (b) the cue should have a strong immediate impact that decays quickly. In the third phase of our research, we attempted to design or engineer a sleeper effect (see Greenwald, Pratkanis, Leippe, \& Baumgardner, 1986) by using operations capable of producing these differential rates of cue and message decay.

\section{Experiments 13 and 14}

One possible reason Experiment 11 did not produce a sleeper effect was the lack of residual message impact after a delay. In Experiment 13, we attacked this problem by designing a procedure to induce positive cognitive responses toward the message and thus strengthen its delayed impact. As a consequence of the Experiment 13 results, we added a source-rating task (comparable to one used by Gruder et al.) in Experiment 14, to draw attention to the source and increase its immediate impact.

\section{Method}

In Experiments 13 and 14, subjects viewed the short policy messages in a 3 (source credibility: low, undescribed, or high) $\times 10$ (measurement delay) design. (The source cue always appeared after the message.) The undescribed source (serving as the message-only treatment) was a note indicating that information about the source of the message was unavailable at the present time. To increase the statistical power of the sleeper effect tests, half of the messages were presented in the low-credible source treatment with the other half of the messages divided equally among the undescribed (message-only) and high-source treatments.

To strengthen the impact of the message, subjects in both Experiments 13 and 14 were asked, after reading each message, to identify the argument that they considered the best. Specifically, subjects (a) viewed each persuasive message, (b) wrote down on a slip of paper the best argument in the message, (c) put the slip of paper in a slot-top box provided for this purpose, and (d) pressed a button to reveal the source of the information. For Experiment 14, we added a fifth task designed to assure attention to the source cue. In particular, the source information appeared on the subject's display screen along with a 15 -point scale (ranging from $1=$ untrustworthy to $15=$ trustworthy), that subjects then used to rate the source.

\section{Results}

Figure 3I presents the opinion data from Experiment 13. The message strengthening procedure appeared to be successful in producing greater opinion change in Experiment 13 compared with Experiments 10 and 11, but also reduced the impact of the discounting cue as indicated by the disappearance of the source credibility effect on message acceptance, $F(1,19)<1$. A sleeper effect was not obtained in the low-credible treatment: a linear trend test yielded a positive but nonsignificant effect of measurement delay on opinion change, $t(19)=.23$, ns. Communication impact declined slightly, but not significantly, in the high-credible and neutral-source treatments (both $p s>.15$ ).

Figure 3J presents the opinion data from Experiment 14 . The source rating task used in this experiment was successful in minimizing immediate opinion change in both the high- and low-source treatments. A sleeper effect of borderline significance occurred in the low-credible source treatment, $t(59)=$ $1.94, p<.06$. The effect was significant in a subsidiary analysis that removed the data for three weak, unpersuasive messages, $t(59)=2.06, p<.05$.

The initial message discounting that occurred in the highcredible source treatment (see Figure $3 \mathrm{~J}$ ) is an anomaly. This discounting effect dissipated as a function of delay, yielding a marginal sleeper effect in the high-credible source treatment, $t(59)=1.87, p<.1$. The data from the source-rating task indicated that subjects perceived the low-credible source as less trustworthy $(M=5.6)$ than the undescribed source $(M=7.1)$, which was in turn rated as less trustworthy than the high-credible source, $M=10.7, F(2,118)=161.35, p<.001$. However, the impact of messages did not differ as a function of source credibility, $F(2,118)<1$. One plausible interpretation of this result is that the source-rating task drew subjects' attention to the persuasion attempt, producing an immediate suppression of message acceptance.

\section{Phase 4: Replicating the (New) Sleeper Effect}

Experiment 14's sleeper effect was weak in magnitude. Given that the effect was strengthened by removing weak, unpersuasive messages, in Experiments 15 and 16 we attempted a replication by using stronger messages.

\section{Experiments 15 and 16}

\section{Method}

In Experiments 15 and 16, each long policy message was presented in a 3 (source credibility: low, undescribed, or high) $\times 10$ (measurement delay) design under the same conditions as those used in Experiment 14. That is, subjects (a) viewed a long policy message, (b) wrote the argument they considered best on a slip of paper, (c) placed the slip of paper in a box, (d) pressed a button to reveal the source, and (e) rated the trustworthiness of the source before being asked (after randomly varied delays) for their opinion on the message topic.

Experiment 16 followed the same procedures but included a stronger source discounting manipulation (in response to the Experiment 15 results). This source manipulation was accomplished by a series of four added display pages of instruction that educated subjects on how to use source information. In the first display of this series the host of "You Should Know" stated:

Since "You Should Know" is a forum for ideas of all types, we do not want to censure any individual or group. However, the home viewer should be wary of information coming from untrustworthy 
sources. Therefore to help you evaluate each letter, we have tried to contact each letter writer to find out where they obtained their information. This will be reported immediately after each letter.

Next, subjects were told that letters presented on previous shows had, unfortunately, come from sources of questionable reliability. This was followed by a persuasive message arguing that public water supplies should not be fluoridated. The next display presented a message, ostensibly from the American Dental Association, refuting the antifluoridation arguments and identifying the previous message's source as "a home viewer who obtained her facts from 'Your health, Your Karma'a magazine devoted to ridding Western society of all man-made health aids." Additional examples of unreliable sources were then presented and discussed.

\section{Results}

Figure $3 \mathrm{~K}$ presents the opinion data from Experiment 15. As shown, all three cue treatments resulted in substantial initial opinion change that increased slightly as a function of measurement delay. The test for the sleeper effect in the low-source treatment was not significant, $t(21)=0.64, n s$. Similarly, communication impact in both the high-credible source and neutralsource treatments did not significantly increase or decline across measurement delay ( $p s>.2$ ). Subjects continued to rate the high-credible source as more trustworthy $(M=7.02)$ than the low-credible source, $M=3.25, t(21)=17.90, p<.001$. Nevertheless, the source information appeared to result in little immediate discounting of the messages. Thus, it appears that the use of the longer policy messages strengthened message impact but resulted in diminished immediate discounting effects, a state of affairs similar to the first use of the message strengthening procedure in Experiment 13.

Figure 3L presents the opinion data for Experiment 16. As can be seen, a strong, immediate discounting effect occurred, perhaps due to the enhanced source instructions. A linear sleeper effect was not obtained in the low-credible source treatment, $t(39)=0.09$, $n s$. However, as shown in Figure $3 \mathrm{~L}$, the quadratic effect was significant, $t(39)=2.59, p<.01$, indicating that a sleeper effect occurred in the early measurement delays followed by a loss of impact. ${ }^{4} \mathrm{~A}$ marginal sleeper effect also occurred in the high-credible source treatment: linear test $t(39)=$ $1.73, p<.1$ and quadratic test $t(39)=1.56, p<.15$. Subjects immediately discounted messages attributed to high-credible sources (as in Experiment 14), even though they continued to rate the low-credible sources as less trustworthy $(M=3.20)$ than the high-credible sources $(M=6.79, t(39)=21.49$, $p<.001)$.

\section{Meta-Analytic Summary of Experiments 1-16}

Collectively, the 16 computerized experiments (which produced 26 tests of the sleeper effect) point to the critical importance of presenting the discounting information after the message for obtaining a sleeper effect. Of the 26 computerized sleeper effect tests (in Phases 1-4), 5 produced a statistically significant result, and 4 of those occurred when the discounting cue information was given after the message. The effect of the timing-of-source-information variation could be seen most clearly when results were combined across studies. The weighted average magnitude (see Footnote 2 ) of the sleeper effect was $d=.065, t(12)=3.23, p<.01$, for 13 conditions in which discounting information came after the message. In contrast, the average effect for 13 conditions in which discounting information came before or with the message was slightly in the negative (decay of persuasion) direction, average $d=-.016$, $\iota(12)=0.65, n s$.

\section{Phase 5: Replicating the Sleeper Effect With Converging Operations}

Many differences exist between the procedures with which Gruder et al. (1978) produced a sleeper effect and our computer-controlled procedures in Experiments 1-16. Some of these procedural differences include: (a) style of discounting cue (message disclaimer vs. source description); (b) persuasive setting (a single message vs. a message-dense environment); (c) measurement delays ( 6 weeks vs. activity units in a single session); (d) presentation format (booklet vs. computer-controlled video display); (e) message length (long, 1000-word message vs. short, 80- to 150-word messages); and (f) message topics (one message on the 4-day work week vs. sets of consumer and policy messages). Because of these potentially important differences, the finding that timing of discounting cue information is critical in Experiments 1-16 does not establish that Gruder et al.'s results depend on their use of the cue-after-message procedure. Accordingly, the conclusion that timing of discounting information is important for a sleeper effect can be strengthened by replicating Gruder et al.'s procedures, while adding a condition in which the discounting cue precedes the message.

\section{Experiment 17}

Experiment 17 replicated Gruder et al.'s Experiment 2 with two added treatments. Subjects were assigned to one of five treatments in which they received: (a) Gruder et al.'s 4-day work week message and their strongest discounting cue presented (as in the Gruder et al., 1978, study) after the message; (b) the same message and cue, with the discounting cue presented before the message; (c) a shortened version of the 4-day work week message followed by the discounting cue; and (d) message-only and (e) no-message controls (both also used by Gruder et al.). All five of our treatments used repeated measurement of opinions at immediate and delayed posttests (the procedure for half of the subjects in Gruder et al.'s study). We expected that if the timing of the cue is critical for producing the sleeper effect, then an effect should occur when the cue is given after the message but not when it is given before. Further, if message strength (or length) is important for obtaining the sleeper effect, then the sleeper effect should be reduced in magnitude with a shorter message.

\section{Method}

Subjects. The subjects were 400 students who received course credit for their participation. Of these students, 294 (73.5\%) were successfully

\footnotetext{
${ }^{4}$ Tests for quadratic trends were routinely performed in the previous experiments. In no case other than for Experiment 16 was a significant quadratic delay function obtained.
} 
contacted by telephone at the 6-week delayed posttest. Returners and nonreturners did not differ significantly in immediate posttest opinion (within each experimental treatment).

The persuasive message. The persuasive message was the same 1000word message arguing against the 4-day work week that was used by Gruder et al. (1978). In addition, we created a shorter version (300 words) by constructing a summary sentence corresponding to each paragraph of the longer message. Subjects in the no-message treatment read an unrelated article (on innovation in science) of comparable length and difficulty.

The discounting cue. The discounting cue was Gruder et al.'s strongest cue manipulation (of which they termed low credibility level 2 with reactance). This discounting cue was a note from the editor (of the magazine in which the persuasive message supposedly had appeared) stating:

Since this article went to press, new research evidence on this topic has been released. In our next issue we will report the findings of a comprehensive study that demonstrates the conclusion of this article is false, and, in fact, the opposite is true--namely that the 4day work week does not produce major problems and increases employee satisfaction.

In addition, such phrases as, "you must inevitably conclude" and "any intelligent person has no choice but to believe" were included in either the first (in the cue-before treatment) or last (in the cue-after treatments) paragraph of the message to create psychological reactance. Subjects exposed to the message-only treatment received a neutral cue (after the message), stating that future articles would appear on this topic.

Procedure. Subjects (in groups of 20 to 30 ) reported to a classroom for an experiment on information processing. They received a booklet from a pile that had been prepared so that subjects would be arbitrarily assigned to one of the five treatments. The first page of the booklet contained an overview of the experiment along with informed consent materials. Also printed on the first page were instructions asking subjects to read the upcoming message in the following manner:

Please read each paragraph in the article twice. Read each paragraph, first for what is said (content). Then read the same paragraph again (before going on to the next), this time paying attention to how it is said (style). As you read underline the main point of each paragraph.

Subjects in the short message treatment were told to read the message only once.

The next pages of the booklet contained one of the five message and cue arrangements followed immediately by a page on which subjects evaluated the communicator and the style of the message. The six critical opinion measures (to be explained in the next section) appeared on the next two pages, embedded in a collection of eight other measures on other topics. Subjects then listed their thoughts about various controversial topics in a filler task unrelated to this study. (The Gruder et al. study did not include this filler task.) The first experimental session ended with a request for subjects' home telephone number (ostensibly in connection with the filler task). Subjects worked independently and took between 20 and 40 min to complete the experimental tasks.

We conducted the delayed posttest session approximately 6 weeks later. Each subject was telephoned at home and asked to participate in a "University Interest Survey." Subjects were not informed about this follow-up interview in the first session. Presumably, each session was perceived as an independent study. In the posttest session, a survey interviewer (unaware of to which treatment the subject was assigned) administered the delayed opinion measure along with a memory test for the cue. At the conclusion, the interviewer debriefed the subject about the goals of the experiment.

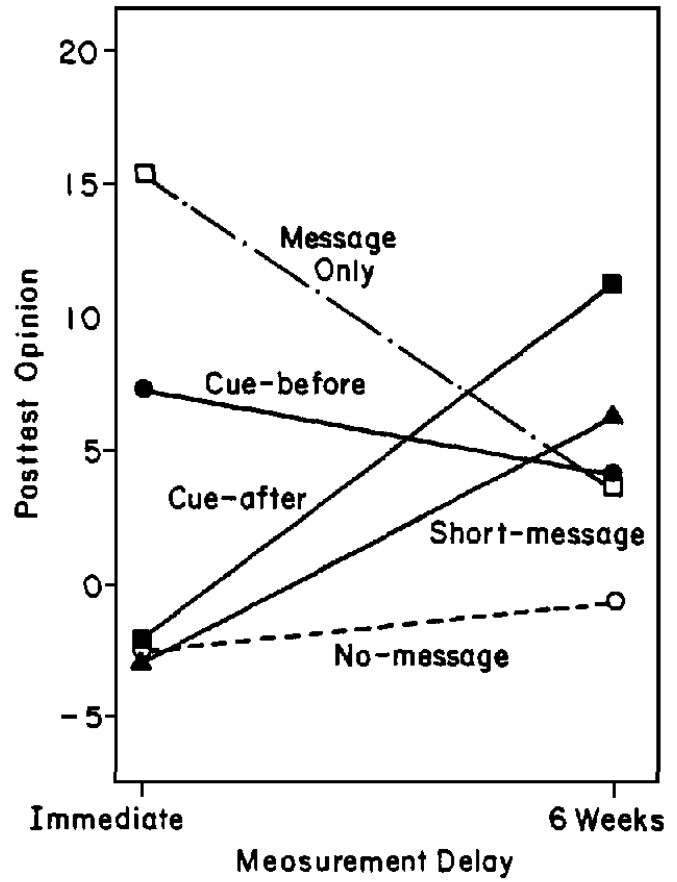

Figure 4. Results of Experiment 17. A significant sleeper effect was obtained when the discounting cue followed the message, a finding that replicates the original Gruder et al. (1978). (The scale ranges from -60 to +60 , with larger numbers representing more persuasion.)

Measures. Opinions toward the 4-day work week were assessed on six separate scales of agreement (three positively and three negatively worded). The response scales ranged from -10 (strongly disagree) to +10 (strongly agree). Each subject's opinion was determined by summing the scores from the six scales (after first reversing the negatively worded items) so that scores could range from -60 (strong disagreement with the message) to +60 (strong agreement - that is, strong opposition to the 4-day work week).

The source-credibility rating was collected using eight bipolar scales ranging from -5 to +5 , anchored with such terms as untrustworthy/ trustworthy, inaccurate/accurate, and false/true. We obtained sourcerating scores for each subject by summing across the eight scales, such that high scores reflected greater perceived source credibility (range $=$ -40 to +40 ).

A funnel interview was taken at end of the telephone survey to assess memory for the cue. The funnel interview consisted of an ordered series of questions asking: (a) Where had the subject recently encountered information on the 4-day work week? (b) Did the subject remember the experiment? (c) Was the article read in the experiment biased? (d) Was there a note from the editor? and finally, (e) What did the note say?

\section{Results}

Figure 4 presents the mean posttest opinion data for Experiment 17 . In the two discounting-cue-after-message treatments, immediate posttest opinion was near the no-message control treatment. However, after a 6-week delay, posttest opinion increased to yield a significant sleeper effect when the discounting cue was given after the longer message, $F(1,114)=8.40, p<$ 
.01 by an interaction test ${ }^{5}$, and a marginal sleeper effect when it was given after the shortened message, $F(1,122)=2.95, p<$ .1. Conversely, no sleeper effect was obtained when the discounting cue was given before the message. The cue-beforemessage treatment resulted in moderate initial opinion change that dissipated slightly (and nonsignificantly) over the delay interval, $F(1,121)=1.15$. The message-only treatment produced the most immediate opinion change, but this change decreased significantly by the sixth week, $F(1,114)=8.25, p<.01 .^{6}$

The mean trustworthiness ratings were consistent with subjects' immediate opinion responses. Subjects receiving only the message rated the source as most trustworthy $(M=14.65)$, followed by subjects receiving the discounting cue before the message $(M=6.04)$. Subjects receiving the cue after the message $(M=2.88)$ and after the shortened message $(M=-1.42)$ rated the source as least trustworthy.

The funnel interview conducted at the 6-week delay indicated that many subjects had forgotten the discounting cue information. Fifty percent of the subjects who received the message mentioned the experiment as a source of recent information on the 4-day work week. However, only $8.4 \%$ of the subjects could correctly recall the content of the note from the editor (i.e., the discounting information).

\section{General Discussion}

\section{Summary of Empirical Findings}

\section{No Sleeper Effect With the Usual Discounting Cue- Before Manipulation}

Most previous sleeper effect studies presented a discounting cue before the persuasive message. Experiments 1-12 and 17 contained 14 experimental treatments that presented a discounting cue before a message. These treatments failed to produce reliable sleeper effects.

\section{A Reliable Sleeper Effect With Novel Procedures}

Two lines of research, varying widely in procedures, have now converged in identifying a set of operations for producing a sleeper effect. Sleeper effects were obtained in studies by Gruder et al. and in our Experiments 14, 16, and 17, by having subjects (a) note the important arguments of the message, (b) receive a discounting cue immediately after the message, and (c) rate the credibility of the message source immediately after receiving the discounting cue and before the immediate posttest opinion assessment.

\section{Magnitude of the Sleeper Effect}

The sleeper effect of Gruder et al. (our Experiment 17) was considerably stronger (using the magnitude of effect $d$ measure) than were those obtained with the computer-controlled procedure of Experiments 1-16. This strong effect, together with the long (6 weeks) posttest delay of Experiment 17 may warrant more confidence in this sleeper effect than in the weak effects and short delays of the computerized studies. Nevertheless, the Experiment 17 result was obtained with a single topic. The mes- sage opposing the 4-day work week may be particularly well suited to producing a sleeper effect. (Gruder et al. did not obtain a sleeper effect in their attempt with another message, which argued against a recently enacted law allowing motorists to turn right at a red stoplight.) The broad range of policy and consumer topics used in Experiments 1-16 warrants confidence in the generalizability of the sleeper effect, although it is a clearly weak effect. Had the Gruder et al. research, or our own Experiment 17, covered a broad array of topics, perhaps they too would have found only a weak sleeper effect (i.e., by combining data across a diverse set of topics).

\section{High-Credible Source Discounting}

One unexpected finding was the immediate discounting of a message when it was paired with a high-credible source. In our first 12 experiments, messages from a high-credible source produced more persuasion than those attributed to a low-credible source. This source credibility effect disappeared in Experiment 13 (and the following studies) when subjects were asked to indicate the best argument in each message. Other researchers have found that source effects fail to occur when a message is scrutinized by a recipient (cf. Chaiken, 1980; Johnson $\&$ Scileppi, 1969; Petty, Cacioppo, \& Goldman, 1981; or Sternthal, Phillips, \& Dholakia, 1978, for a review). In Experiments 14 and 16 , message discounting and marginal sleeper effects were obtained in high-credible source treatments. The trustworthiness rating used in Experiments 14-16 may have drawn attention to the persuasion attempt and to the possibility of untrustworthy information, thereby producing resistance to persuasion. This failure to create a successful high-credibility condition is plausibly a consequence of our within-subjects design. Subjects exposed to only the accepting cue might have shown the expected credibility effect.

\footnotetext{
${ }^{5}$ The Experiment 17 analysis used the same significance testing method as did Gruder et al. (1978). That is, a sleeper effect is indicated by a significant Discounting Cue $\times$ Measurement Delay interaction using only the data from the no-message and appropriate discounting cue treatments. Simple regression analyses of the Experiment 17 data obtained results similar to the analyses of variance (ANOVAs).

${ }^{6}$ The large decrease in opinion in the message-only treatment meant that Gruder et al.'s (1978) fourth logical condition was not met in Experiment 17 . That is, there was not enough residual impact of the message to produce a sleeper effect. To test for this condition, Gruder et al. (1978, p. 1064) suggested a sleeper effect ratio (SER). This ratio compares the difference between immediate opinion in a discounting treatment with delayed opinion in the message-only treatment. A significant difference indicates that there is enough residual message impact to produce a significant sleeper effect. SER for the cue-after treatment in Experiment 17 is $\langle(106)=1.23, p>.2$. Taken literally, this means that a sleeper effect should not have been found in this study, even though, of course, one was obtained. This finding should not be accepted as evidence against the logical analysis of the sleeper effect provided by Gruder et al. It is perhaps more appropriate to note that a $95 \%$ confidence interval constructed for the delayed opinion mean of the message-only treatment would range up to an opinion score of 10,6 . This upper value provides more than enough room for a sleeper effect to occur, SER of $c(106)=$ $2.79, p<.01$.
} 


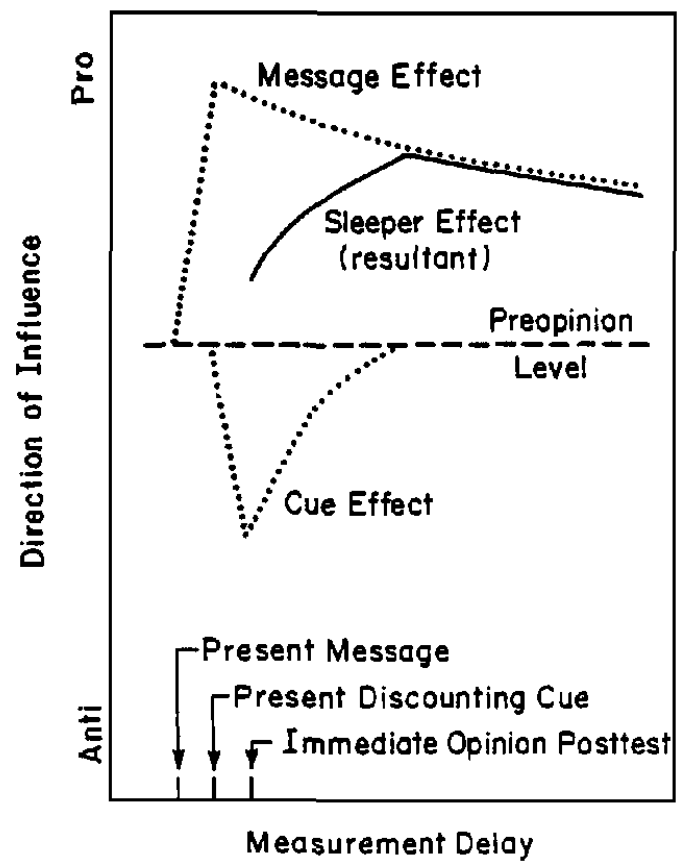

Figure 5. The differential decay explanation of the sleeper effect. (At short delays, message and discounting cue are hypothesized [dotted lines] to have near equal impact. However, the impact of the cue dissipates rapidly to yield an observable [solid line] sleeper effect.)

\section{Theoretical Interpretation: The Differential Decay Sleeper Effect}

The failure to obtain a sleeper effect using the usual cue-before procedure and the development of a new set of operations capable of producing a reliable sleeper effect raises concerns about the use of the dissociation hypothesis as an explanation of our results. Instead, we favor a new formulation of the sleeper effect based on the primacy-recency analysis first proposed by Miller and Campbell (1959). This new sleeper effect can be termed a differential decay sleeper effect.

\section{The Differential Decay Interpretation}

Figure 5 illustrates the differential decay interpretation of the sleeper effect. Hypothesized message and cue effects (represented by dotted lines) are assumed to have strong initial impacts (albeit in opposite directions) that decay in the expected fashion. Observed effects (the solid line) are based on the combined impact of message and cue. A sleeper effect results when message and cue have near equal initial impact, but the impact of the cue decays more rapidly and independently than that of the message. Thus, once considered to be an exception to the usual expectation that the effects of a message diminishes with time, the sleeper effect constitutes, according to the differential decay interpretation, yet another illustration of the rule.

If one considers the discounting cue as an opposing communication, the differential decay sleeper effect is similar to the delayed primacy effect first obtained by Miller and Campbell
(1959). In their study, subjects received two messages in close succession. At immediate measurement delays, the second message (or a discounting cue in the research presented here) was most influential in determining persuasion, whereas delayed opinions were most swayed by the first communication (a delayed primacy effect). Miller and Campbell interpreted their result as evidence that overall persuasive impact was determined by the summed impact of the two messages, assuming a slower decay rate for the first message.

Previous experiments on delayed primacy effects (see Insko, 1964; Miller \& Campbell, 1959; Wilson \& Miller, 1968) have identified two conditions that must be met for the effect to occur: (a) slower rate of impact decay for the first message than the second (or discounting cue) and (b) weak immediate integration of information from the two communications. The three sleeper effect operations we have identified in this article help ensure that these differential decay conditions are met. The note-the-best-argument procedure prolongs the persistence of message impact. The discounting-cue-after-message manipulation strengthens immediate cue effects without necessarily lengthening its persistence function. The trustworthiness rating also strengthens the immediate cue impact and likely hinders the integration of message and cue impact in memory by focusing attention on the characteristics of the discounting cue.

According to the differential decay interpretation, a sleeper effect is not likely to occur when discounting information precedes the message. In such cases, subjects may be more disposed to counterargue with the message as they read. Thus, the persuasive impact of the message is attenuated, and the message and source are more likely to form a unit in memory.

\section{Comparison of Forgetting Interpretations of the Sleeper Effect}

The dissociation and differential decay interpretations of the sleeper effect are similar in that both claim the sleeper effect is based on forgetting and retention processes as opposed to other processes (see McGuire, 1985; Pratkanis, 1981). However, they differ as to how information is organized at encoding and what information is retained over time.

The dissociation hypothesis assumes that message, discounting cue, and topic category are integrated or associated in memory at time of encoding. As time passes, the cue information dissociates (or separates) from the topic/message representation or, as Gruder et al. (1978) state, "Dissociation refers to the spontaneous breakdown of the pairing between message conclusion and discounting cue" (p. 1062). According to the dissociation hypothesis, delayed opinion change is based on the retrieval of message arguments accompanied by the failure to retrieve a dissociated discounting cue. In contrast, the differential decay hypothesis assumes that the impact of message and cue are poorly integrated at time of encoding. Rather than the dissociation process, a simpler process- the decay of persuasionis responsible for the differential decay sleeper effect.

The dissociation and differential decay hypotheses also differ in what type of information is coded and stored in memory. Originally, Hovland et al. (1949) proposed that the sleeper effect was based on the forgetting of the source. On finding that sub- 
jects in a sleeper effect treatment could remember source information, Hovland and Weiss modified the original source-forgetting hypothesis to one of dissociation (i.e., less of an association between message and cue). This reformulation preserved their learning theory approach to persuasion. An alternative explanation of their results is that subjects remember the communication events (episodes), but the impact of the communication (on evaluation) decays over time. This assumption is made in the differential decay interpretation. Thus, it is not the dissociation of events in memory but a differential dissipation of the impact of two different persuasive communications. This is consistent with the notion of two separate memory systems (Tulving, 1983): one for episodes or events (i.e., 1 heard a message and cue) and one for meaning (i.e., I favor $X$ ).

We prefer the differential decay interpretation as the next evolution of the forgetting hypothesis of the sleeper effect for four reasons. First, the dissociation hypothesis fails to predict the reliable finding that the timing of the cue presentation is important in producing a sleeper effect. According to the dissociation hypothesis, a sleeper effect should occur regardless of how message/cue information is encoded as long as the memorial link between message and cue spontaneously weakens over time. Second, the dissociation hypothesis never made explicit the need to calibrate the rate of decay for message and cue impact. (The logical requirements of Gruder et al. were one attempt to clarify this requirement). Third, the differential decay hypothesis relates the sleeper effect to other, well-established persuasion findings, especially the delayed primacy effects first obtained by Miller and Campbell (1959) and subsequently replicated by Insko (1964) and Wilson and Miller (1968). Fourth, the differential decay interpretation suggests operations beyond those used in our studies that may be capable of producing delayed persuasion effects. For example, Ronis (1980) produced a differential-decay based effect by having subjects devote extra study time to one of a pair of opposing communications. (Future research may identify cue-before operations capable of producing differential decay of impacts and weak integration of cue and message and, thus, a sleeper effect.)

\section{Concluding Remarks}

One indication of scientific progress is the specification of an increasingly complete list of the conditions needed to produce an effect and, just as important, conditions under which the effect will not occur. The history of research on the sleeper effect can be characterized as a series of studies, each limiting the conditions under which a sleeper effect should be obtained (see Greenwald et al., 1986, p. 221), with each new finding contributing to the evolution of the forgetting interpretation of the sleeper effect.

The set of studies presented in this article began with the hypothesis that the sleeper effect is a small effect requiring a powerful, well-controlled experimental procedure for its detection. In the research that followed, other factors-timing of a discounting cue, rates of decay of message, and cue impact-were identified as important for obtaining a sleeper effect. Although, the dissociation hypothesis could be modified to explain these factors, it nonetheless appears to have abdicated its sleeper effect claims, and the "old" sleeper effect-the one that has been sought in experiments that merely presented a discounting cue before an otherwise effective message-remains dormant and moribund (cf. Gillig \& Greenwald, 1974). However, a new differential decay interpretation, one that serves as a more powerful summary of the empirical results, has appeared as heir to the sleeper effect throne. It is, of course, readily conceivable that still another interpretation, one that more powerfully describes conditions under which a sleeper effect is and is not obtained, will eventually replace the now reigning differential decay interpretation.

\footnotetext{
${ }^{7}$ The dissociation interpretation can be modified to account for the timing-of-cue finding, if it is suggested that placing the cue after the message somehow aids the dissociation process. The differential decay hypothesis makes this modification by supposing that message and cue impact are not initially well when the cue follows the message, and thus, there is no need for the dissociation of discounting cue from topic/message information.
}

\section{References}

Baumgardner, M. H., Leippe, M. R., Ronis, D. L., \& Greenwald, A. G. (1983). In search of reliable persuasion effects: II. Associative interference and persistence of persuasion in a message-dense environment. Journal of Personality and Social Psychology, 45, 524-537.

Capon, N., \& Hulbert, J. (1973). The sleeper effect-an awakening. Public Opinion Quarterly, 37, 333-358.

Chaiken, S. (1980). Heuristic versus systematic information processing and the use of source versus message cues in persuasion. Journal of Personality and Social Psychology. 39, 752-766.

Cohen, J. (1977). Statistical power analysis for the behavioral sciences (Rev. ed.). New York: Academic Press.

Cohen, J., \& Cohen, P. (1975). Applied multiple regression/correlation analysis for the behavioral sciences. Hillsdale, NJ: Erlbaum.

Cook, T. D. (1971). The discounting cue hypothesis and the sleeper effect. Unpublished manuscript, Northwestern University, Evanston, IL.

Cook, T. D., \& Flay, B. R. (1978). The persistence of experimentally induced attitude change. In L. Berkowitz (Ed.), Adrances in experimental social psychology (Vol. 1I, pp. 1-57). New York: Academic Press.

Cook, T. D., Gruder, C. L., Hennigan, K. M., \& Flay, B. R. (1979). History of the sleeper effect: Some logical pitfalls in accepting the null hypothesis. Psychological Bulletin, 86, 662-679.

Gillig, P. M., \& Greenwald, A. G. (1974). Is it time to lay the sleeper effect to rest? Journal of Personality and Social Psychology, 29, 132139.

Greenwald, A. G., Pratkanis, A. R., Leippe, M. R., \& Baumgardner, M. H. (1986). Under what conditions does theory obstruct research progress? Psychological Review, 93, 216-229.

Gruder, C. L., Cook, T. D., Hennigan, K. M., Flay, B. R., Alessis, C., \& Halamaj, J. (1978). Empirical tests of the absolute sleeper effect predicted from the discounting cue hypothesis. Joumal of Personality and Social Psychology, 36, 1061-1074.

Hennigan, K. M., Cook, T. D., \& Gruder, C. L. (1982). Cognitive tuning set, source credibility, and attitude change. Journal of Personality and Social Psychology, 42, 412-425.

Hovland, C. I., Janis, I. L., \& Kelley, H. H. (1953). Communication and persuasion: Psychological studies of opinion change. New Haven, CT: Yale University Press.

Hovland, C. I., Lumsdaine, A. A., \& Sheffield, F. D. (1949). Experi- 
ments on mass communications. Princeton, NJ: Princeton University Press.

Hovland, C. I., \& Weiss, W. (1951). The influence of source credibility on communication effectiveness. Public Opinion Quarterly, 15, 635-650.

Insko, C. A. (1964). Primacy versus recency in persuasion as a function of timing of arguments and measures. Journal of Abnormal and Social Psychology, 69, 381-391.

Johnson, H. H., \& Scileppi, J. A. (1969). Effects of ego-involvement conditions on attitude change to high and low credibility communicators. Joumal of Personality and Social Psychology, 13, 31-36.

Kelman, H. C., \& Hovland, C. I. (1953). "Reinstatement" of the communicator in delayed measurement of opinion change. Journal of Abnormal and Social Psychology; 48, 327-335.

Maddux, J. E., \& Rogers, R. W. (1980). Effects of source expertise, physical attractiveness, and supporting arguments on persuasion: A case of brains over beauty. Joumal of Personality and Social Psychology, 39, 235-244.

McGuire, W. J. (1985). Attitudes and attitude change. In G. Lindzey \& E. Aronson (Eds.), Handbook of Social Psychology (3rd ed., Vol. 2, pp. 233-246). Reading, MA: Addison-Wesley.

Miller, N., \& Campbell, D. T. (1959). Recency and primacy in persuasion as a function of timing of speeches and measurements. Journal of Abnormal and Social Psychology, 59, 1-9.

Petty, R. E., Cacioppo, J. T., \& Goldman, R. (1981). Personal involvement as a determinant of argument-based persuasion. Journal of Personality and Social Psychology, 41, 847-855.

Pratkanis, A. R. (1981). A hunt for the sleeper effect in persuasion. Unpublished master's thesis, Ohio State University, Columbus.
Pratkanis, A. R., Greenwald, A. G., Ronis, D. L., Leippe, M. R., \& Baumgardner, M. H. (1986). Consumer product and socio-political issue messages for use in studies of persuasion. Personality and social Psychology Bulletin, 12, 536-538. (Complete manuscript available in ERIC Document Reproduction Service, \#ED 269 826).

Ronis, D. L. (1980). Repetition and agreement with opposing arguments: A delayed action effect. Journal of Experimental Social Psychology, 16, 376-387.

Ronis, D. L., Baumgardner, M. H., Leippe, M. R., Cacioppo, J. T., \& Greenwald, A. G. (1977). In search of reliable persuasion effects: I. A computer-controlled procedure for studying persuasion. Journal of Personality and Social Psychology, 35, 548-569.

Sternthal, B., Phillips, L. W., \& Dholakia, R. (1978). The persuasive effects of source credibility: A situational analysis. Public Opinion Quarterly, 42, 285-314.

Tulving, E. (1983). Elements of episodic memory. New York: Oxford University Press.

Weiss, W. (1953). A "sleeper" effect in opinion change. Joumal of Abnormal and Social Psychology, 48, 173-180.

Whittaker, J. O., \& Meade, R. D. (1968). Retention of opinion change as a function of differential source credibility: A cross-cultural study. International Journal of Psychology, 3, 103-108.

Wilson, W., \& Miller, H. (1968). Repetition, order of presentation, and timing of arguments and measures as determinants of opinion change. Journal of Personality and Social Psychology, 9, 184-188.

Appendix

\section{Examples of Persuasive Messages with Cues and Measures}

\section{Short Policy Message: People Should Use Detergents Containing Phosphates}

Among the detergents on the market, those lacking phosphates are generally more expensive than those that have phosphates. Given the economic reality of our time, detergents with phosphates should be used until others can compete with them in the marketplace.

If used moderately (as in household use), phosphate detergents are an insignificant source of pollution. Complaints about these detergents may well be part of a campaign by representatives of heavy industry to place guilt on consumers and divert it from themselves.

\section{Opinion Response Scale for the Short Policy Message}

People should use detergents containing phosphates

\section{Long Policy Message: Should Phosphate-Containing Detergents be Permitted for Household Use?}

In ordinary household use, phosphate detergents are insignificant as a source of environmental pollution. It is the phosphates used in heavy industry and agriculture that are significant as sources of pollution. Very possibly, the publicity against phosphates for home use is part of industry's campaign to focus guilt on consumers-at the same time, diverting attention from their own massive polluting activities.

More importantly, there is no good alternative to phosphates for home use. Phosphate detergents are considerably less expensive and far superior in cleaning ability to those lacking phosphates. Phosphate detergents allow most clothes to be cleaned less often and, thus, the clothes can last longer. Finally, and almost unnoticed in this debate, is the fact that nonphosphate detergents often contain E.D.T.A. as a chemical additive. E.D.T.A. has not yet been studied thoroughly, but is potentially a damaging pollutant. It is wisest to continue to permit phosphates in home detergents until we have something better to replace them.

\begin{tabular}{|c|c|c|c|c|c|c|c|c|c|c|c|c|c|}
\hline 1 & 2 & 3 & 4 & 5 & 6 & 7 & 8 & 9 & 10 & 11 & 12 & 13 & 14 \\
\hline & & & & Disagree & & & Unce & & & Agree & & & $\begin{array}{l}\text { Agree } \\
\text { strongly }\end{array}$ \\
\hline
\end{tabular}


Opinion Response Scale for the Long Policy Message

Should phosphate containing detergents be permitted for household use?

\begin{tabular}{|c|c|c|c|c|c|c|c|c|}
\hline 1 & 2 & 3 & 4 & 5 & & 7 & 8 & 9 \\
\hline \multicolumn{3}{|c|}{$\begin{array}{l}\text { certainly no, } \\
\text { phosphates should } \\
\text { not be permitted } \\
\text { in detergents }\end{array}$} & \multicolumn{3}{|c|}{ uncertain } & \multicolumn{3}{|c|}{$\begin{array}{l}\text { certainly yes, } \\
\text { phosphates should } \\
\text { be permitted in } \\
\text { detergents }\end{array}$} \\
\hline
\end{tabular}

\section{Discounting Cue (Used with Long and Short Policy Message)}

A soap company sent me a pamphlet containing this information when I asked them why the value of my stock in their soap company had declined recently. They feel strongly that people should use detergents containing phosphates.

\section{Accepting Cue (Used with Long and Short Policy Message)}

A government agency sent me a pamphlet containing this information when I asked them if phosphates were dangerous. They feel strongly that people should use detergents containing phosphates.

\section{A Consumer Product Message: Wilson Automobiles}

If a car has good brakes, it will have a short stopping distance. This stopping ability should be maintained when the car is braked repeatedly and the brakes should work in panic stops when the brakes are slammed on while the car is moving at highway speed. Good brakes are obviously important for safety.

Wilson automobiles have excellent brakes with short stopping distances and high reliability, which contribute to safety.

The noise level inside a car depends on many things including the shape of the car, the quality of the suspension and the exhaust system, and of course, the speed and the smoothness of the road. These noises affect more than comfort; a noisy car contributes to driver fatigue and ability to notice or respond to unsafe conditions.

Wilson automobiles are excellent in quietness. This contributes substantially to comfort and safety.

Opinion Response Scale for the Consumer Product Message How would you rate Wilson Automobiles?

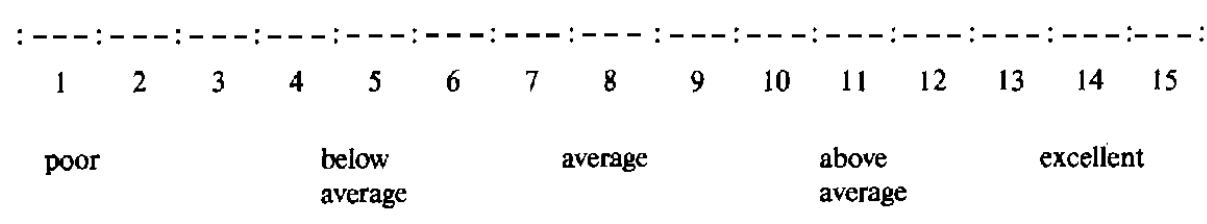

Received December 23, 1985

Revision received June 4, 1987

Accepted June 4, 1987 